\title{
Keynotes
}

\section{Higher training: what is it trying to achieve and what is its rationale?}

\author{
John Copeland*, Professor and Head of Department of Psychiatry, The University of \\ Liverpool, Liverpool University Hospital, Liverpool L69 3BX
}

This paper attempts to address the question, "What is higher training for?". It then tries to explain some of the principles which have guided the work of the Joint Committee on Higher Psychiatric Training (JCHPT) up to now, and which are sometimes misunderstood by trainers and trainees, and finally, discusses some current problems. The views expressed should not be taken as reflecting the future policy of the JCHPT.

The JCHPT is a joint committee of the Royal College of Psychiatrists and the Association of University Teachers of Psychiatry; as such it tends to reflect the structure of training in other medical specialties. Because it is responsible to two parent bodies it has traditionally preserved a degree of independence from either. It was founded in 1973 after the foundation of the College, in conjunction with the Joint Higher Training Committees of the other Royal Colleges, at the invitation of the then DHSS, and its first Chairman was Sir Martin Roth followed by Professors Walton, Rawnsley, Gelder, Mindham and Copeland. In August 1991 Professor Paykel succeeded to the Chair. There still seems to exist much uncertainty about what it is that higher training in psychiatry is aiming to achieve.

Firstly, higher training must be put in the context of other training received by psychiatrists and indeed by doctors as a whole. We must also be clear about our perception of the role of the psychiatrist of the future otherwise we will be on shaky ground when other professions lay claim to the psychiatrist's traditional territory. Much mental illness is now managed in general practice by community nurses and psychologists. The latter have for many years competed in some areas with psychiatry and have recently won the right to prescribe medication in parts of the United States. The former are also pressing for certain prescribing rights. The argument that they are cheaper to train overall is a powerful

* Chairman, JCHPT 1988-1991. Based on a paper delivered to the Summer Quarterly Meeting of the Royal College of Psychiatrists, Brighton 1991. one. Nor should psychiatrists hold on to areas of practice if professional divisions are changing in response to changing need. These divisions are not sacrosanct. In the same way some psychiatric colleagues express the fear that if, for example, schizophrenia wanders into the organic diagnostic category, it will be taken over by neurologists in much the same manner that dementia is already their prerogative in the United States.

\section{If medical doctors have been trained for a unique role, what should we be training psychiatrists for?}

By their training in a range of basic medical subjects including both the biological and social sciences, doctors should have developed a broad overview of the needs of their patients and the views of their professional colleagues. Few other professions concerned with care have this broad background which underpins their clinical experience and prepares them to be the natural leaders of a therapeutic team. However, as a profession we may have to face that there are certain of our activities which others can perform more cheaply and with possibly equal efficacy.

The medical training fits doctors for applying and monitoring physical treatments in a way that is not open to other professional carers, but there is nothing peculiar in their training which uniquely fits them for providing, for example, psychotherapy or behaviour therapy.

Within the medical profession, psychiatrists should not be seduced into believing they should only treat diseases where the aetiology is obscure or psychological, the 'functional illnesses', while leaving 'organic' illness to the neurologists.

Psychiatrists would seem best suited to sorting out disease and disability which is expressed by the patient predominantly in psychological terms or where there are psychological or cultural reasons why physical symptoms appear to have replaced 
psychological ones. We should therefore be training doctors in the recognition and management of diseases predominantly affecting the mind, regardless of aetiology.

So far, the approach to training has been aimed at preserving traditional distinctions and practices. In our wisdom, like other specialties, we have divided professional training into two levels, "general" and "higher", a division about which the General Medical Council has recently expressed serious reservations. Unlike many other specialties, the senior registrar level in psychiatry is the first intermediate grade where trainees undertake the supervision of junior staff. Senior house officers and registrars are regarded as more or less interchangeable, there being no trainees in the house officer grade. Thus the organisation of higher training in psychiatry differs from that in some specialities, particularly in not recognising post membership registrar experience as contributing to higher training except in the special circumstance of full-time research.

In general professional training we emphasise the sciences basic to psychiatry and to an understanding of the practice of professional colleagues. We aim also to provide trainees with a broad grasp of psychiatric clinical skills and practice and how to evaluate their own performance. Special attention is given not only to skills peculiar to doctors such as diagnosis and investigation, application of physical treatments and the assessment of prognosis but also to the practice of psychological treatments and the function of the therapeutic team members.

\section{What then is the purpose of higher training?}

Higher training is concerned firstly with the consolidation of the skills and knowledge learnt during general professional training and secondly with the preparation for consultantship or professional equivalent which involves learning team co-ordination, the attributes of leadership, decision-making, service planning, the development of innovative approaches to care, and management skills, as well as respect for the contributions of other workers and the training of junior doctors and medical students. Trainees are also expected to learn the importance of keeping abreast of knowledge and of acquiring a wider understanding of research techniques and methods of audit. Thirdly, they will train in a sub-speciality which may be general and old age psychiatry, child and adolescent, mental handicap or forensic psychiatry, psychotherapy, or in one of a growing number of areas such as substance abuse, community psychiatry, or rehabilitation, which have not yet achieved sub-speciality status.

TABLE I.

Some principles of higher training

1. Higher training requires a competent teacher as a role model

2. Must include both role modelling and experiential training

3. Service must not take precedence over training

4. The senior registrar must not "act down"

5. Clinical training must be varied and flexible

6. Academic time must not be eroded

7. Training must match the needs of trainees

8. Must match the future needs of services

9. Must give more attention to preparation for management

10. Must prepare trainees for modern practice

11. Should encourage not discourage research

12. Academic posts must

(a) protect time

(b) have varied clinical experience

13. Should take place in good working conditions

\section{Some principles of higher training}

Table I lists some of the principles on which higher training is based.

1. Higher training has always required competent teachers who are themselves adequately trained to serve as role models.

In future, consultants appointed before having completed training or where training is not considered adequate may no longer be acceptable as trainers. Part of the trainer's job is to comment on performance and to correct errors of practice. This is why unsupervised experience, such as happens in locum consultant or clinical assistant posts, cannot be counted as a training period unless it takes place towards the end of training when it may help to smooth the transition to a substantive consultant post. The Committee spends much time assessing the suitability of posts and trainers which is why it has not been able to accept clinical experience gained abroad unless it has been approved by the Committee in advance, as part of a training programme.

2. Training must include both role modelling and experiential training.

Trainees must have "hands on" experience and be themselves involved in the making of clinical decisions. Observation is not enough.

3. Service needs must not take precedence over training needs.

It has been a long standing principle of higher training that trainees are "supernumerary to the service". That does not mean that they do not 
take an active part in the work of the service, how else would they have "hands on" experience? But it does mean that the service needs must not take precedence over training. The involvement in the running of the service is only to facilitate training, that is to say, trainees must not be used to fill gaps in the service which have no educational value for them. Trainers sometimes ask, what happens to clinics which trainees have started, when they come to leave? This suggests that the trainee has been used as "a pair of hands" and the service has come to depend on their contribution. On the whole, trainees should not generate new work, they should take over existing work from the trainer and hand it back at the end of their training period. In this way the trainer gains some time for the supervision of the trainee. Those in control of an organisation will generally seek to orientate that organisation to their own convenience unless they are constantly aware of this possibility and able to resist it.

4. The trainee must not "act down".

Clearly, if a senior registrar trainee is required to act like a registrar, he or she is merely repeating training already accomplished. It is no argument that consultants themselves act down, which they often do; it is not adequate training. Of course, occasional acting down may be done as a favour but it should not be expected and therefore become a regular occurrence.

5. Clinical training must be varied and flexible.

This has generally been achieved by having in schemes more training slots than funded posts, thus allowing trainees to chose slots which match the experience they need. Too many extra slots, however, may impair the continuity of a scheme.

6. Academic time must not be eroded.

The Committee has repeatedly emphasised that neither academic nor research time should be eroded by clinical commitments. This is perhaps the rule which is most disregarded and one which the committee has been most determined to uphold. The trainees themselves are often the culprits and the trainers need to actively encourage them to participate in these activities.

7. Training must match the needs of the trainees. It may be necessary to supplement experience missed in general professional training or to allow for special interests such as in community psychiatry or rehabilitation. Trainees must not be appointed to posts for the convenience of trainers, e.g. the practice of allocating a senior registrar to a clinical director or chairman of the committee in order to help out with the service commitment.
8. However, training must also match the future needs of the service.

Training scheme organisers have been urged to try to arrange slots in shortage sub-specialities and to anticipate the future needs of the service. They have been encouraged to obtain the view of the Committee on any interesting and unusual slots they would like to arrange.

9. Preparation for management.

Many of us would prefer not to be involved in management but it has become a fact of life in the newly re-organised health service. Psychiatrists must be prepared to play their part, so it is essential that schemes now make adequate provision for this experience. The Committee has decided to look more keenly at the extent of the management training a scheme provides.

10. Training schemes must encourage research. Sometimes trainers have doubts about the usefulness of training in research, usually those who have never undertaken it themselves. There is probably no evidence to show that skills developed pursuing research generalise to other areas of activity, but unfortunately that is true about most of the things we teach. It is hoped that the experience of research will inculcate a spirit of enquiry and a knowledge about where to find information, and rekindle an imagination which our medical educational system has spent years attenuating by an over emphasis on didactic teaching. It should stimulate a critical approach to our own practice and that of others, and encourage the challenging of inherited dogma. If it generates a sceptical approach to clinical opinion and clinical impression it will have done its job. On a more direct level, it should teach how to evaluate the research claims of others and the value of one's own practice, and provide a method for testing out the clinical hunch. It is always possible that the work undertaken may itself advance knowledge and the trainee should certainly be working to that aim. In internal medicine and surgery, where the competition for consultant posts is high, it is expected that the trainee will sit for a research degree; we should expect no less from our trainees in psychiatry.

The JCHPT has recently taken steps to make it easier for trainees in full-time research posts to have up to four years of their research experience approved for higher training. Previously this was only available to trainees employed by MRC units. However, it is essential in order to gain approval from the Committee to meet certain criteria, and to apply for approval in advance for periods longer than one year. 
11. Academic posts must (a) protect academic time, (b) have varied clinical experience.

Protecting academic time may sound strange when referring to academic posts but in some centres lecturer posts were created, one suspects, out of posts which were otherwise difficult to fill. Often such posts continued with their training content unchanged. Some years ago the Association of University Teachers of Psychiatry, expressed concern about the extent and quality of academic training in these posts and asked the Committee to assess their academic content and ensure that each had a minimum of four academic sessions. If this should not be the case, the posts may be approved as senior registrar appointments and not as lecturers. The Committee has not made a distinction between lecturer posts funded by the NHS and those funded by the Department of Education and Science through the Universities Funding Council.

The Committee has also been concerned that lecturers should have a varied clinical experience. The occupants of such posts ought to be "high fliers" who might be expected to look after themselves. However, there have been cases brought to the attention of the Committee, of lecturers who have spent up to three years or more of their training undertaking clinical duties in the same highly specialised units. Statistics show that the majority of academic medical staff eventually enter the National Health Service, so their need for an adequate clinical training is clear. A careful balance has to be struck between the needs of the university who is paying the bill and the future needs of the health service. It is probably wise that the clinical content of the lecturer's post should be reviewed by the scheme organizer who would advise the head of the university department of his or her views.

12. Training should take place in good working conditions.

On the whole, working conditions in psychiatry have greatly improved over recent years. However, there are still some black spots which should no longer be acceptable as places for patient care. If they are not acceptable for patient care they should not be acceptable for training. It is likely that in the future, a more critical look will be taken at the physical conditions within which training is taking place.

\section{Some problems facing Higher Training Committees}

There are difficulties maintaining standards of training during times of change. As a consequence the Committee has shown an increasing reluctance to grant approval for as long as five years however good a scheme may appear to be, on the grounds that changes may happen suddenly and can alter conditions over night.

There is also the problem of "changing goal posts". Scheme organisers often complain that they have fulfilled all the criteria set after a previous visit only to find that the Committee is still not satisfied. This is because standards continue to rise and the expectations of the JCHPT rise with them. All schemes have had time to put their houses in order and there is now no reason for unsatisfactory slots. The Committee has been prepared to take action over poor posts with greater vigour.

There is the serious position of doctors who have trained abroad outside the EC and the equally difficult problem of those who have trained in other countries of the EC, and who now look for recognition in this country. Similarly, there are in this country doctors who have misguidedly taken locum posts, not infrequently with the strong encouragement of their chiefs, who now find themselves regarded as untrained. The Committee has had diffculty seeing how it could offer help to such people except to point out that JCHPT has no control over Advisory Appointments Committees and can only seek to influence decisions through the Royal College Advisers. If untrained doctors apply for posts, they may find themselves appointed even though the Royal College Adviser does not approve of the appointment. Such doctors may, however, not be approved by the JCHPT for the training of junior psychiatrists.

There may be difficulties ahead as a consequence of changing arrangements following the Government's White Paper. Posts may be held at Region but whether or not this also includes salaries is not clear at present.

There are anecdotes about Trusts which encourage research, perhaps because it is seen as prestigious, but also about fears that research and training may be discouraged because they absorb resources which have to be paid for. At present the Department of Health disallows the advertising of posts which have not received JCHPT approval. It would be of great importance for training that this position is not weakened.

There has been a problem with some posts in the private sector. The JCHPT has never been opposed in principle, to approving posts in the private sector. In practice, such posts have been unable to match requirements for higher training. Trainees still need to be aware of posts incorrectly described as having "senior registrar" status but advertised by the private hospitals, and which do not have educational approval. The recent introduction of " $T$ " registration by the General Medical Council has 
disadvantaged a number of doctors who chose not to complete their higher training but to go straight into private practice. They are now having difficulty acquiring specialist status. The JCHPT can do no more than make recommendations to the College about whether a psychiatrist meets the criteria for inclusion on the "specialist register" and this recommendation is based on the duration of approved higher training.

\section{Are there dangers which the Higher Training Committee should try to avoid?}

Is the training course for psychiatry now too long? Given three years of general professional training and four years of higher training, the period is probably too long, but is in line with other specialties. The Department of Health in their document Achieving a Balance put forward the tentative proposal for combining registrar and senior registrar grades.

Why do we need higher training anyway? For many years those who served on training committees and zealously developed the rules often had no formal training themselves. Higher training is essential in order to ensure a basic level of skills which all trainees will attain and thus avoid the considerable variations in competence which used to occur. In spite of training some trainees are never likely to attain even the basic level and they will hopefully be recognised by the system at an early stage.

The high flier would be expected to achieve the basic level of competence in a much shorter time and generally does, rarely going the full four years before being appointed to a consultant post. Provided the local training scheme organisers are satisfied with progress, this should not be discouraged. It is one of the flexible advantages which psychiatry has retained by avoiding the registration of completion of training at the end of four years.

A danger which continues to permeate through most of British medical education, and which we should try to avoid, is the way we stifle the initiative and creative instincts of our students by over education of the wrong kind with a far too great a dependence on the retention of fact rather than how to assemble knowledge and use it. There is, also, the danger of over complicating training rules so that they become too difficult for anyone to administer.
Is higher training satisfactory and if so, where does it go from here?

In the past the JCHPT has been successful in the improvement which it has brought about in British psychiatry. There has been a considerable rise in standards across the country. Nevertheless, in future, the JCHPT may have to address its own audit procedures. How will it quantify the improvement it appears to bring about? Will it be necessary to interview consultants after appointment in order to assess consumer satisfaction? Postgraduate deans may wish to have a measure of what it is they are paying for.

Are the present funding arrangements for the Committee satisfactory? The grant in aid from the DOH only partly covers the cost of the work of the Committee and the rest still comes out of the pockets of the members and fellows of the College. No doubt this was a sacrifice they were willing to make in the early stages of the profession in order to start the upgrading of training standards. Now that it is an established part of medical audit, should the Committee's services not reflect the customer/provider ethos? In this way postgraduate deans would be obliged to buy the Committee's services, even perhaps purchasing additional approval visits if they thought fit. The question is under consideration by the Committee but a number of concerns have been voiced about the introduction of such changes.

Should continuing professional training not be part of higher training? The College has now invited a member of the JCHPT to sit on the relevant College committee.

Finally, it seems that the JCHPT or something like it will go on as long as higher training continues to be separated from general professional training. The committee will certainly need its own particular orientation in order to ensure that the knowledge gained in general professional training is properly applied towards learning and practising the consultant role.

\section{Acknowledgement}

The author would like to thank both Professor Gene Paykel, Chairman, and Miss Suzanna Goodwyn, Administrative Secretary to the JCHPT, for their invaluable help over the years and for reading the manuscript and making a number of important suggestions and amendments which have been adopted. 